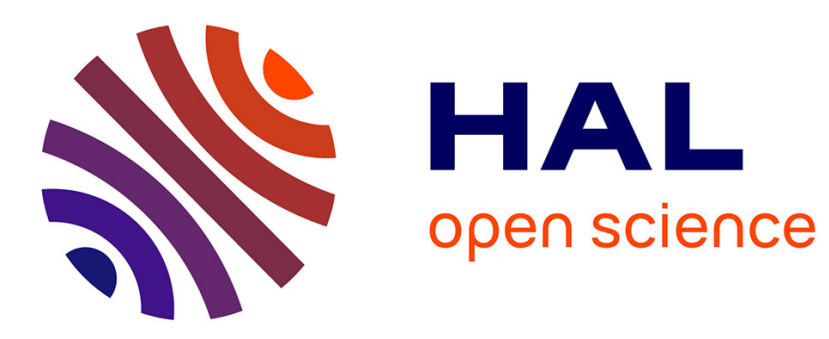

\title{
High frequency and wide range of human kidney papillary crystalline plugs
}

Léa Huguet, Marine Le Dudal, Marine Livrozet, Dominique Bazin, Vincent

Frochot, Joëlle Perez, Jean-philippe Haymann, Isabelle Brocheriou, Michel

Daudon, Emmanuel Letavernier

\section{To cite this version:}

Léa Huguet, Marine Le Dudal, Marine Livrozet, Dominique Bazin, Vincent Frochot, et al.. High frequency and wide range of human kidney papillary crystalline plugs. Urolithiasis -Springer-, In press, 46 (4), pp.333-341. 10.1007/s00240-017-1031-9 . hal-01822535

\section{HAL Id: hal-01822535 \\ https://hal.sorbonne-universite.fr/hal-01822535}

Submitted on 25 Jun 2018

HAL is a multi-disciplinary open access archive for the deposit and dissemination of scientific research documents, whether they are published or not. The documents may come from teaching and research institutions in France or abroad, or from public or private research centers.
L'archive ouverte pluridisciplinaire HAL, est destinée au dépôt et à la diffusion de documents scientifiques de niveau recherche, publiés ou non, émanant des établissements d'enseignement et de recherche français ou étrangers, des laboratoires publics ou privés. 


\title{
High frequency and wide range of human kidney papillary crystalline plugs
}

\author{
Léa Huguet ${ }^{1,2}$. Marine Le Dudal ${ }^{1,2} \cdot$ Marine Livrozet $^{1,2} \cdot$ Dominique Bazin $^{3,4} \cdot$ Vincent Frochot $^{5} \cdot$ Joëlle Perez $^{1,2}$. \\ Jean-Philippe Haymann ${ }^{1,2,5} \cdot$ Isabelle Brocheriou $^{6} \cdot$ Michel Daudon $^{1,2,5} \cdot$ Emmanuel Letavernier $^{1,2,5,7}$
}

\begin{abstract}
Most of kidney stones are supposed to originate from Randall's plaque at the tip of the papilla or from papillary tubular plugs. Nevertheless, the frequency and the composition of crystalline plugs remain only partly described. The objective was to assess the frequency, the composition and the topography of papillary plugs in human kidneys. A total of 76 papillae from 25 kidneys removed for cancer and without stones were analysed by immunohistochemistry combined with Yasue staining, field emission-scanning electron microscopy and Fourier transformed infrared micro-spectroscopy. Papillary tubular plugs have been observed by Yasue staining in 23/25 patients (92\%) and 52/76 papillae (68\%). Most of these plugs were made of calcium phosphate, mainly carbonated apatite and amorphous calcium phosphate, and rarely octacalcium phosphate pentahydrate. Calcium and magnesium phosphate (whitlockite) have also been observed. Based upon immunostaining coupled to Yasue coloration, most of calcium phosphate plugs were located in the deepest part of the loop of Henle. Calcium oxalate monohydrate and dihydrate tubular plugs were less frequent and stood in collecting ducts. At last, we observed calcium phosphate plugs deforming and sometimes breaking adjacent collecting ducts. Papillary tubular plugging, which may be considered as a potential first step toward kidney stone formation, is a very frequent setting, even in kidneys of non-stone formers. The variety in their composition and the distal precipitation of calcium oxalate suggest that plugs may occur in various conditions of urine supersaturation. Plugs were sometimes associated with collecting duct deformation.
\end{abstract}

Keywords Kidney stone $\cdot$ Calcium $\cdot$ Phosphate $\cdot$ Papilla $\cdot$ Crystal $\cdot$ Plug

\section{Introduction}

Emmanuel Letavernier

emmanuel.letavernier@aphp.fr

1 Sorbonne Universités, UPMC Univ Paris 06, UMR S 1155, 75020 Paris, France

2 INSERM, UMR S 1155, 75020 Paris, France

3 CNRS, Laboratoire de Chimie de la Matière Condensée de Paris, UPMC, Collège de France, Paris, France

4 Laboratoire de Physique des Solides, CNRS UMR 8502, Université Paris Sud XI, 91405 Orsay, France

5 Physiology Unit, AP-HP, Hôpital Tenon, 75020 Paris, France

6 Pathology Unit, AP-HP, Hôpital Tenon, 75020 Paris, France

7 Service des Explorations Fonctionnelles Multidisciplinaires, Hôpital TENON, 4 rue de la Chine, 75020 Paris, France
The prevalence of renal lithiasis has increased over the last decades [1-4]. However, the exact origin of kidney stones is still a matter of debate. Three pathways for initial crystalline germ nucleation and growth have been proposed: (1) nucleation of crystals on a Randall's plaque at the tip of the papilla, (2) growth in renal cavities and (3) formation of tubular plugs [5]. Development of endoscopic procedures has recently allowed to visualize both Randall's plaque and tubular plugs at the tip of papillae. Randall's plaques were first described by Alexander Randall eight decades ago [6]. Randall's plaques are discrete, flat layers of calcification arising in the interstitium of renal papillae. Development of these deposits and urothelium erosion would provide nuclei for calcium oxalate stone formation [7]. These plaques are found in a large number of calcium oxalate stone formers but also in the absence of nephrolithiasis [8]. Tubular plugs are described as apatite deposits in renal tubules. They represent 
a common phenomenon in stone formers [9]. Tubular plugs have been associated with epithelial cell damaging, interstitial fibrosis, papillary scarring and nephron loss [10]. Both Randall's plaques and tubular plugs are thought to be precursors for idiopathic calcium oxalate stone formation [6-10].

Randall's plaque surface has been shown to be related to stone formation risk factors such as the decrease of diuresis volume and urinary $\mathrm{pH}$ and the increase of calciuria [11]. It has also been related to the amount of lithiasis clinical events. Tubular plugs seem to be related to high urinary $\mathrm{pH}$, lower citraturia and increased calcium phosphate supersaturation $[10,12]$. They are thought to be more involved than Randall's plaque in case of stone formation post-bypass surgery, brushite stone, hyperparathyroidism or renal tubular acidosis [10, 12].

We previously analysed human papillae from healthy parts of kidneys removed for cancer [13]. As nephrolithiasis is a very frequent disease affecting more than $10 \%$ of the population, and because urine is a supersaturated milieu, we hypothesized that normal kidney would be the siege of incipient stone formation in tubules and actually, we have been surprised not only by the high frequency of incipient Randall's plaque but also papillary tubular plugs [13]. Our purpose is to perform a descriptive analysis of papillary tubular plugs observed in papillae from non-stone formers. We describe herein that papillary plugs are extremely frequent and present an unexpected variety of crystalline phases. In addition, we observe collecting duct deformation at the contact of tubular plugs formed in the loop of Henle.

\section{Materials and methods}

\section{Papillae collection}

We studied kidneys removed for cancer from 25 patients between 2011 and 2014 as previously described [13]. Patients gave a written consent in the Urology Unit relative to kidney removal and tissue conservation. Therefore, 76 papillae have been anonymously collected and coded after extemporaneous examination and no data relative to patients have been recorded according to French legislation and Helsinki declaration for patient's safety, except for the age and the sex of the patient. Papillae (with adjacent inner and outer medulla) have been embedded in paraffin after fixation by formaldehyde.

\section{Yasue staining and immunohistochemical analyses}

Tissue sections $(4 \mu \mathrm{m})$ have been performed and stained by the Yasue procedure to reveal tissue calcifications. To assess the topography of incipient plugs, Yasue staining has been followed by classical immunostaining. Proximal convoluted tubules and descending loops of Henle were immunostained with a rabbit anti-aquaporin 1 (AQP1) antibody (1:600, SC-20810 clone H-55, Santa Cruz Biotechnology). Ascending loops of Henle were immunostained with a mouse monoclonal anti-Barttin antibody (1:100, SC-365161 clone A-3, Santa Cruz Biotechnology). Distal convoluted tubules and, to a lesser extent, collecting ducts were immunostained with rabbit anti-WNK 4 antibody (1:400, clone NB600-284, Novus Bio). Collecting ducts were immunostained with a goat anti-aquaporin 2 (AQP2) antibody (1:200, SC-9882 clone C-17, Santa Cruz Biotechnology). Samples were revealed with Single Stain MAX PO (mouse, rabbit or goat) Histofine (Nichirei Biosciences, Japan). For negative controls, the primary antibodies were replaced by an equal concentration of rabbit or mouse IgG (Dako).

\section{Field emission-scanning electron microscopy (FE-SEM)}

Tissue sections $(4 \mu \mathrm{m})$ were investigated with a Zeiss SUPRA $^{\mathrm{TM}}$ 55VP field emission-scanning electron microscope (FE-SEM). Measurements were performed at a low voltage $(1.4 \mathrm{keV})$ and without the usual deposits of carbon at the surface of the sample.

\section{FTIR micro-spectroscopy}

Microcalcifications were characterized using Fourier transform infrared micro-spectroscopy ( $\mu$-FTIR). Tissue sections $(4 \mu \mathrm{m})$ were deposited on low-emission microscope slides (MirrIR, Keveley Technologies, Tienta Sciences, Indianapolis). FTIR analysis was performed in serial sections adjacent to tissue sections stained with Yasue technique. FTIR hyperspectral images were recorded with a Spectrum spotlight 400 FT-IR imaging system (Perkin Elmer Life Sciences, Courtaboeuf, France), with a spatial resolution of 6.25 micrometre and a spectral resolution of $8 \mathrm{~cm}^{-1}$. The spectra were recorded in the $4000-700 \mathrm{~cm}^{-1}$ mid-infrared range. Each spectral image covering a substantial part of the tissue consisted of about 30,000 spectra.

\section{Results}

\section{High frequency of tubular plugs}

Among 25 kidneys removed for cancer, we analysed 76 papillae in the healthy parts of the kidney for a median of three papillae per patient. For each patient, we analysed one 4- $\mu \mathrm{m}$-thick section of the papilla, cut in the longitudinal axis. As previously described, we distinguished distal interstitial structures (incipient Randall's plaques) from intratubular plugs [13]. Sixty-eight percent (52/76) of the papillae 
sections and $92 \%$ of the patients (23/25) had tubular plugs observed using Yasue histological techniques. In total, 386 plugs were found (mean five plugs/papilla section); relevant examples are shown in Figs. 1, 2, 3 and 4.
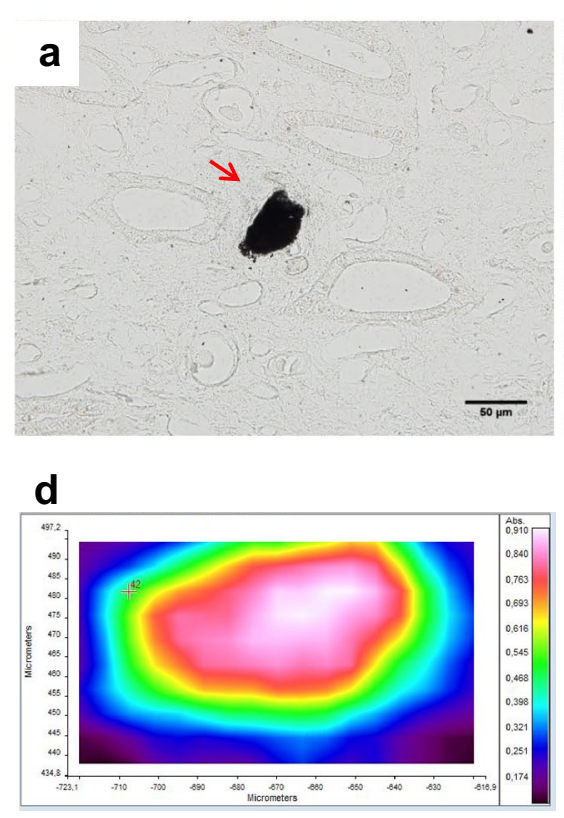
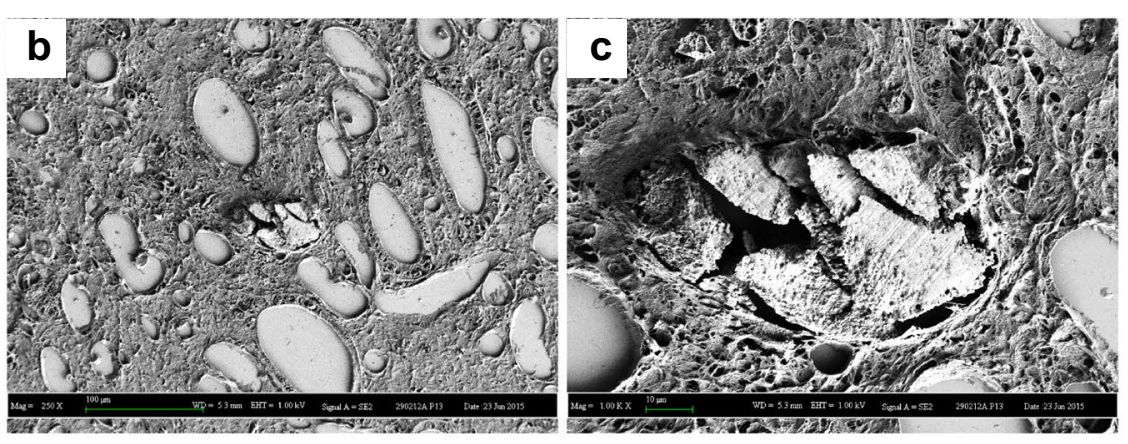

$\mathbf{e}$

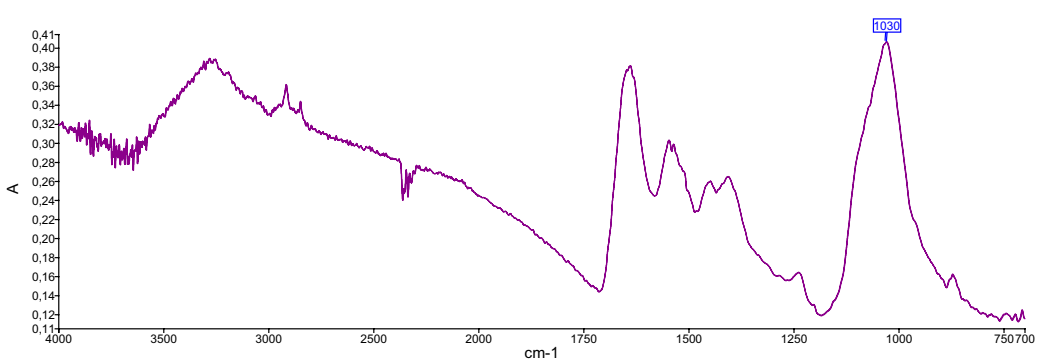

Fig. 1 Carbonated apatite plug. a Yasue staining (photonic microscopy, $\times 600)$ and $\mathbf{b}, \mathbf{c}$ scanning electron microscopy $(\times 250$ and $\times 1000)$. $\mathbf{d}$ Plug reflectance FTIR cartography. e Reflectance spectrum showing a peak at $1032 \mathrm{~cm}^{-1}$, specific for apatite (theoretically around $1030 \mathrm{~cm}^{-1}$ )

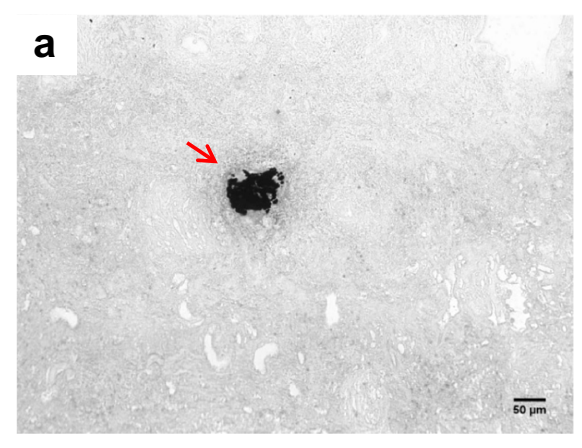

d

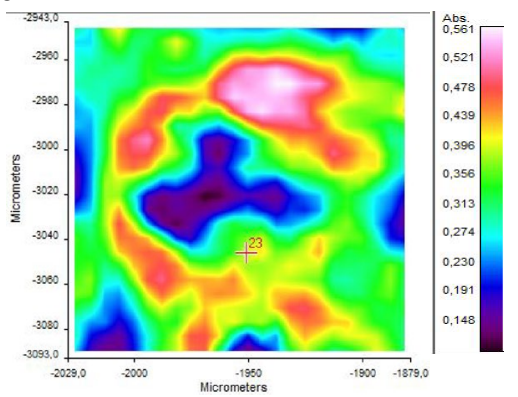

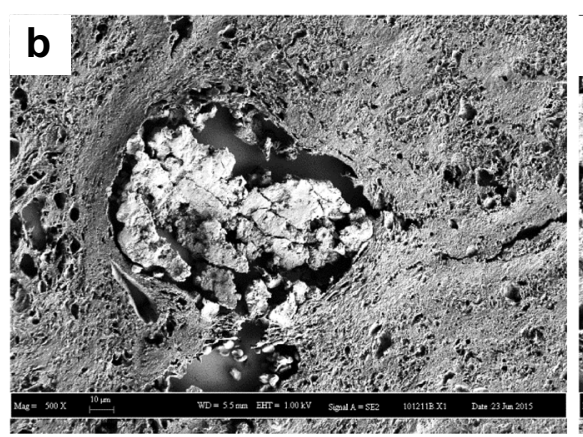

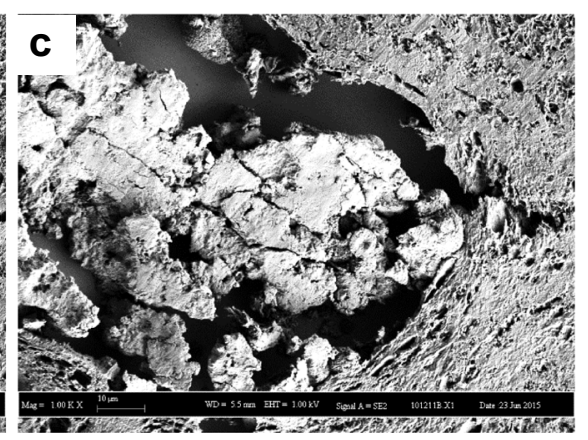

e

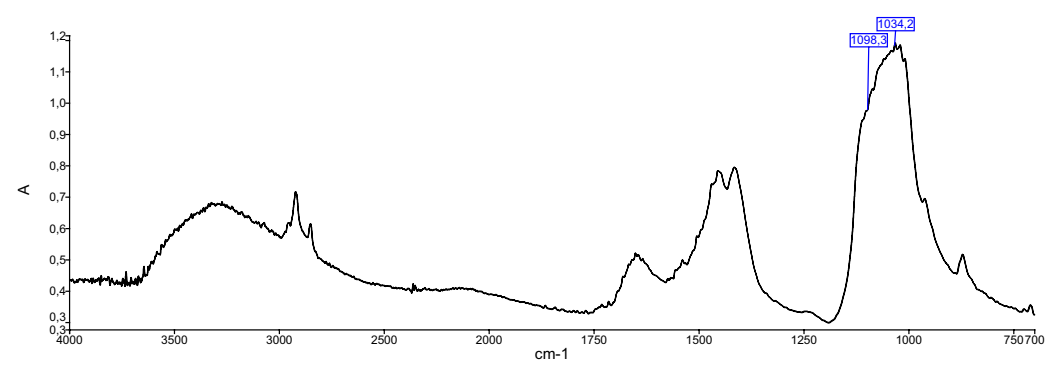

Fig. 2 Mixed carbonated amorphous calcium phosphate (ACCP) and carbonated apatite (CA) plug. a Yasue staining (photonic microscopy, $\times 600)$ and $\mathbf{b}$, c scanning electron microscopy $(\times 250$ and $\times 1000)$. d
Plug reflectance FTIR cartography. e Reflectance spectrum showing a smooth and rounded peak between 1034 and $1098 \mathrm{~cm}^{-1}$ specific for ACCP with a high carbonate rate (peaks at 875 and $1420 \mathrm{~cm}^{-1}$ ) 

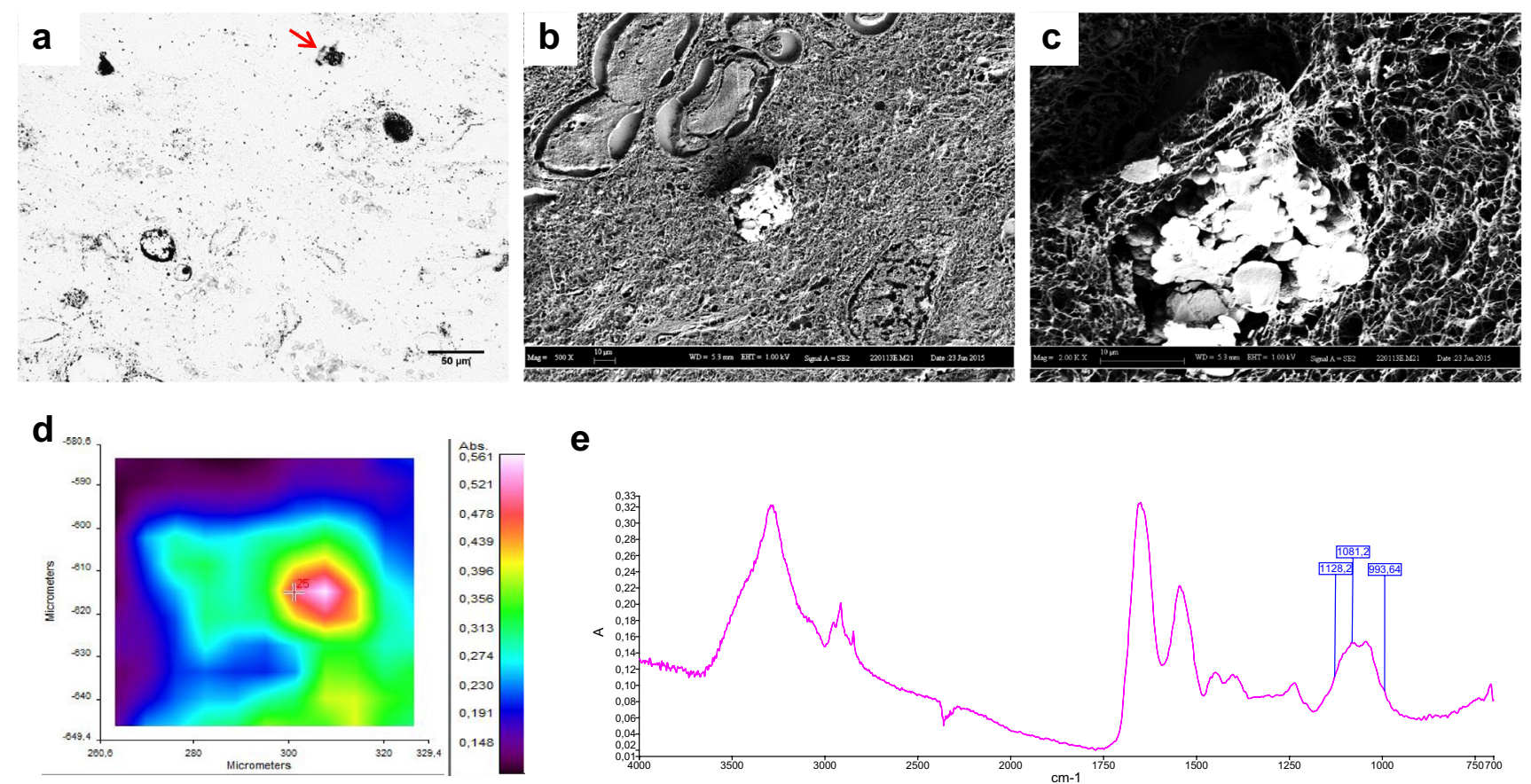

e

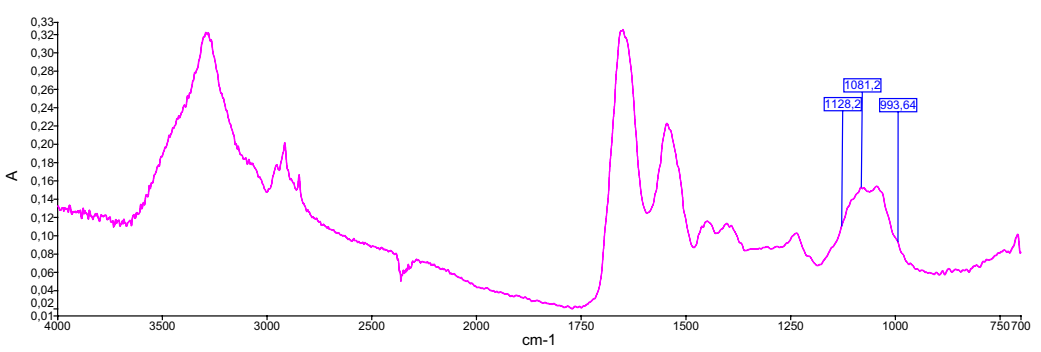

Fig. 3 Whitlockite plug. a Yasue staining (photonic microscopy, $\times 600)$ and $\mathbf{b}$, c scanning electron microscopy $(\times 250$ and $\times 1000)$. d Plug reflectance FTIR cartography. e Reflectance spectrum showing a peak at $1081.2 \mathrm{~cm}^{-1}$ (theoretically around $1080 \mathrm{~cm}^{-1}$ ) with a left shoulder at $1128 \mathrm{~cm}^{-1}$ and a right shoulder at $993 \mathrm{~cm}^{-1}$ specific for whitlockite
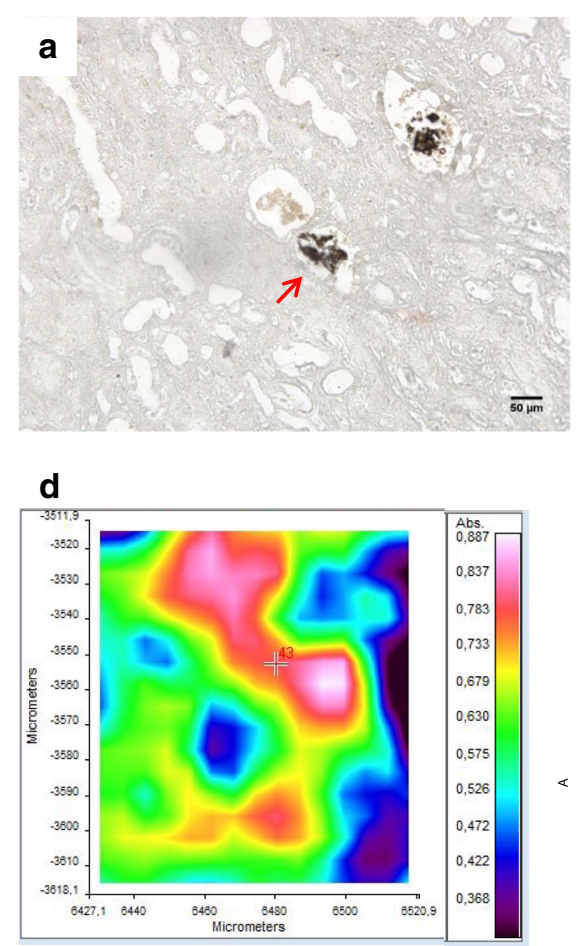

Fig. 4 Calcium oxalate plug. a Yasue staining (photonic microscopy, $\times 600)$ and $\mathbf{b}$, c scanning electron microscopy $(\times 250$ and $\times 1000)$. d Plug reflectance FTIR cartography. e Reflectance spectrum showing peaks at $778.69 \mathrm{~cm}^{-1}$ (theoretically around $780 \mathrm{~cm}^{-1}$ ) and

e
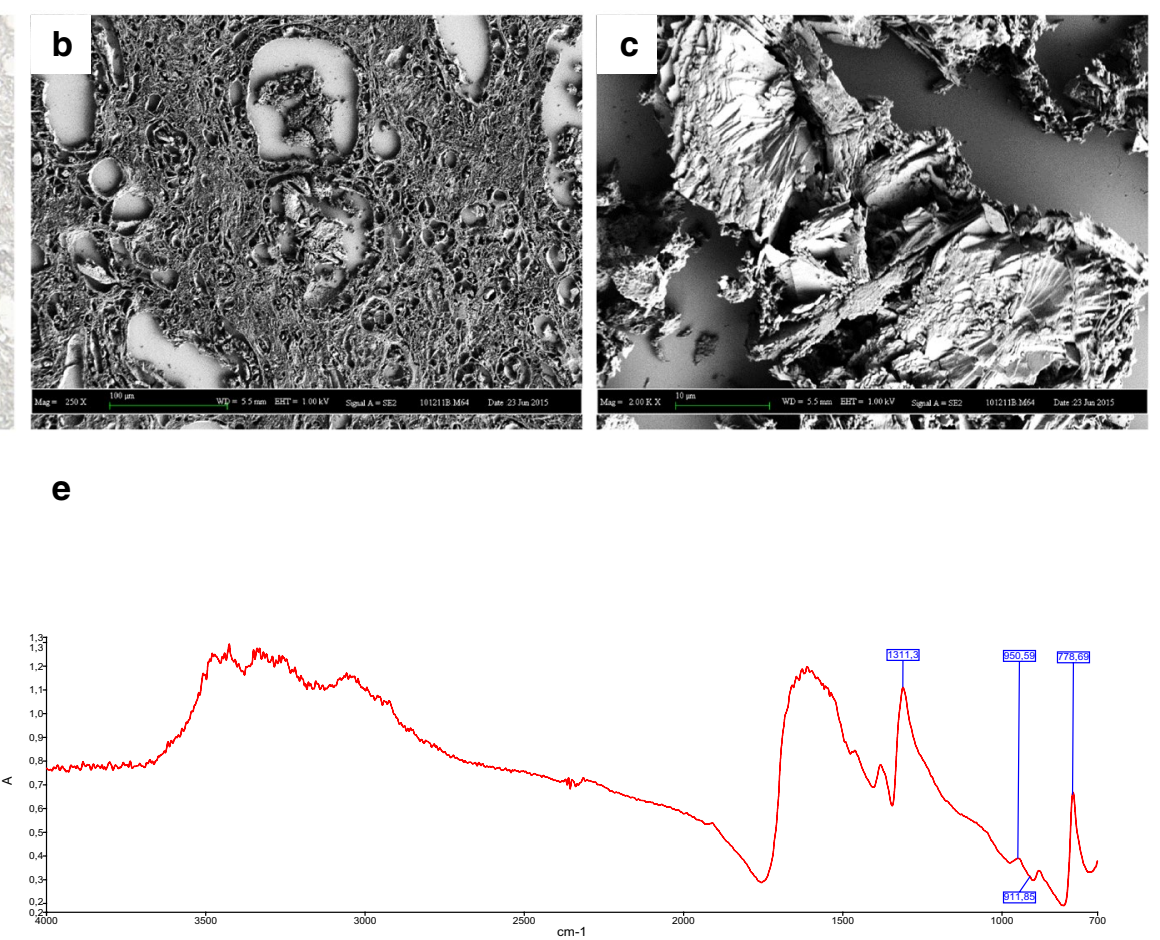

$1311.3 \mathrm{~cm}^{-1}$ (theoretically around $1310 \mathrm{~cm}^{-1}$ ) specific for calcium oxalate and at $911.85 \mathrm{~cm}^{-1}$ (theoretically around $912 \mathrm{~cm}^{-1}$ ) and $950.59 \mathrm{~cm}^{-1}$ (theoretically around $950 \mathrm{~cm}^{-1}$ ) indicating the presence of both COD and COM, respectively 


\section{High variety of crystalline phases forming tubular plugs}

We analysed 110 tubular plugs from 24 papillae (14 patients) by $\mu$ FTIR spectroscopy to characterize crystalline phases. Seven compounds have been identified: carbonated apatite (CA; 90/110), amorphous carbonated calcium phosphate (ACCP; 79/110), calcium oxalate monohydrate (COM; $10 / 110)$, calcium oxalate dihydrate (COD; 5/110), calcium carbonate (calcite; 3/110), whitlockite (3/110) and octacalcium phosphate pentahydrate (OCP; 1/110). The various crystalline phases present in plugs, papillae and patients are summarized in Table 1. Although CA and ACCP were observed in many papillae and patients, OCP was observed in only one individual, calcium oxalate was observed in only one patient (but in several papillae), as well as calcite and whitlockite (Figs. 1, 2, 3, 4).

In many cases, two different crystalline phases were associated components of a single plug (Table 2). The association between CA and ACCP was frequent and identified in $60.9 \%(67 / 110)$ of the plugs. Calcium oxalate was observed in $9.1 \%$ (10/110), either pure COM in 4.5\% (5/110) of plugs or mixed COM + COD in 4.5\% (5/110) of plugs, all these calcium oxalate plugs were observed in only one individual and did not contain calcium phosphate.

\section{Plugs' topography}

We performed Yasue staining coupled to immunohistochemistry to determine plug localisation along the nephron, in 25 papillae, with inner and outer medulla. Proximal convoluted tubules and descending loops of Henle were labelled with anti-aquaporin 1 (AQP1) antibody, ascending loops of Henle with anti-Barttin antibody, distal convoluted tubules with anti-WNK4 antibody and collecting ducts with anti-AQP2 antibody. In most cases, there was no colocalization of tubular plugs with AQP1, AQP2, Barttin or WNK4 staining, evidencing that most of the plugs were present in the deepest part of the loop of Henle (Fig. 5b-d, f). In rare cases, calcium phosphate plugs were found in WNK4-positive structures, i.e. distal tubule (Fig. 5d). A notable exception was the exclusive presence of calcium oxalate plugs in the collecting ducts expressing AQP2 (Fig. 5a).

\section{Tubular remodelling in contact with plugs}

In many patients, calcium phosphate tubular plugs probably present in the thin ascending loop of Henle (not expressing AQP1, Barttin, WNK4 or AQP2) were able to deform and sometimes to tear up the adjacent collecting duct epithelial cells (Fig. 6a-f).

\section{Discussion}

Although urolithiasis is a growing public heath challenge worldwide, the first step of kidney stone formation is still a matter of debate. It seems likely that crystal adhesion to epithelial tubular cells may initiate the process [14]. Cellular and rodent models are of interest to characterize the early phases of stone formation and evidence the importance of calcium oxalate or calcium phosphate tubular plugging [15].
Table 1 Number of plugs, papillae and patients $(\%)$ for each identified crystalline phase

\begin{tabular}{llllllll}
\hline & CA & ACCP & COM & COD & Calcite & OCP & Whitlockite \\
\hline Plugs & $90(81.8 \%)$ & $79(71.8 \%)$ & $10(9.1 \%)$ & $5(4.5 \%)$ & $3(2.7 \%)$ & $1(0.9 \%)$ & $3(2.7 \%)$ \\
Papillae & $24(100 \%)$ & $20(83.3 \%)$ & $3(12.5 \%)$ & $2(8.3 \%)$ & $1(4.2 \%)$ & $1(4.2 \%)$ & $1(4.2 \%)$ \\
Patients & $14(58.3 \%)$ & $12(50 \%)$ & $1(7.1 \%)$ & $1(7.1 \%)$ & $1(7.1 \%)$ & $1(7.1 \%)$ & $1(7.1 \%)$ \\
\hline
\end{tabular}

$A C C P$ amorphous carbonated calcium phosphate, $C A$ carbonated apatite, COM calcium oxalate monohydrate, $C O D$ calcium oxalate dihydrate, $O C P$ octacalcium phosphate pentahydrate

\begin{tabular}{|c|c|c|c|c|c|c|c|}
\hline & CA & $\mathrm{ACCP}$ & $\mathrm{COM}$ & COD & Calcite & OCP & Whitlockite \\
\hline CA & $17(15.5 \%)$ & $67(60.9 \%)$ & 0 & 0 & $3(2.7 \%)$ & $1(0.9 \%)$ & $2(1.8 \%)$ \\
\hline $\mathrm{ACCP}$ & & $9(8.2 \%)$ & 0 & 0 & & 0 & 0 \\
\hline $\mathrm{COM}$ & & & $5(4.5 \%)$ & $5(4.5 \%)$ & 0 & 0 & 0 \\
\hline COD & & & & 0 & 0 & 0 & 0 \\
\hline Calcite & & & & & 0 & 0 & 0 \\
\hline $\mathrm{OCP}$ & & & & & & 0 & 0 \\
\hline Whitlockite & & & & & & & $1(0.9 \%)$ \\
\hline
\end{tabular}

$A C C P$ amorphous carbonated calcium phosphate, $C A$ carbonated apatite, $C O M$ calcium oxalate monohydrate, $C O D$ calcium oxalate dihydrate, $O C P$ octacalcium phosphate pentahydrate
Table 2 Number of plugs containing pure or mixed crystalline phases 

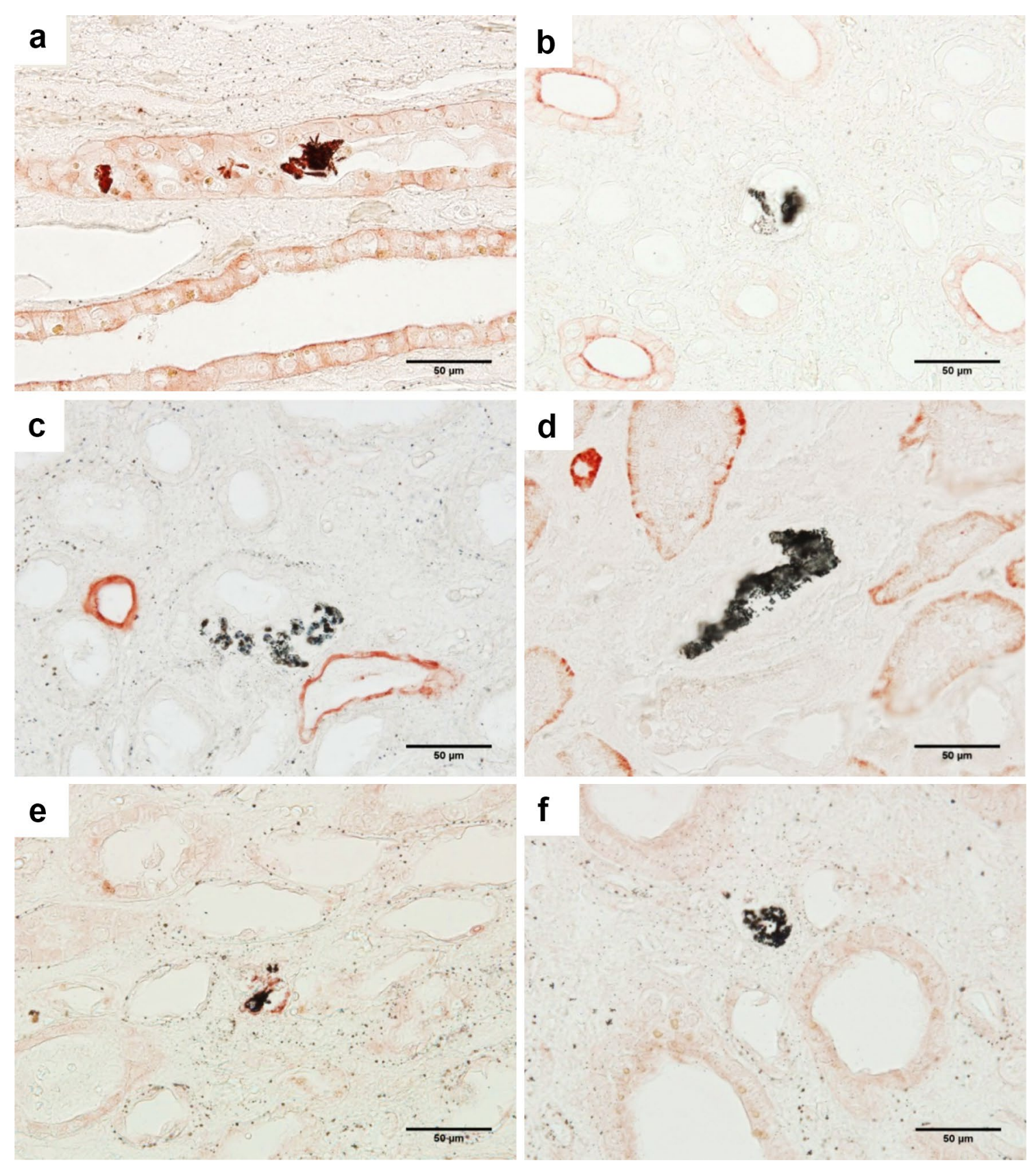

Fig. 5 Immunohistochemistry and Yasue staining (photonic microscopy, $\times 600$ ). a AQP2-positive colocalization (calcium oxalate), b AQP2-negative colocalization (calcium phosphate), c AQP1-negative

colocalization, d Barttin-negative colocalization, e WNK4-positive colocalization, $\mathbf{f}$ WNK4-negative colocalization

Nevertheless, these models do not reproduce human kidney stone disease by many aspects (kidney stone composition, absence of Randall's plaque, etc.). The main purpose of this study was to analyse incipient papillae calcifications to draw up an inventory of the renal calcifications that may be observed in "normal" papillae, and to assess the early processes potentially leading to kidney stone formation.

We have been previously surprised by the frequency of tubular plugs in non-stone formers' kidneys [13]. These

plugs may co-exist with Randall's plaque in the same papilla but their spatial distribution is different: incipient plaques are interstitial deposits limited to the tip of the papilla and surrounding a large number of tubular or vascular lumens, whereas plugs are present inside the tubule, often isolated and sparse in the papilla. Of notice, we analysed a single 4- $\mu$ m-thick section for each papilla, so that we obviously underestimated the frequency of tubular plugs. Even in these limiting conditions, we observed tubular plugs in $92 \%$ of 

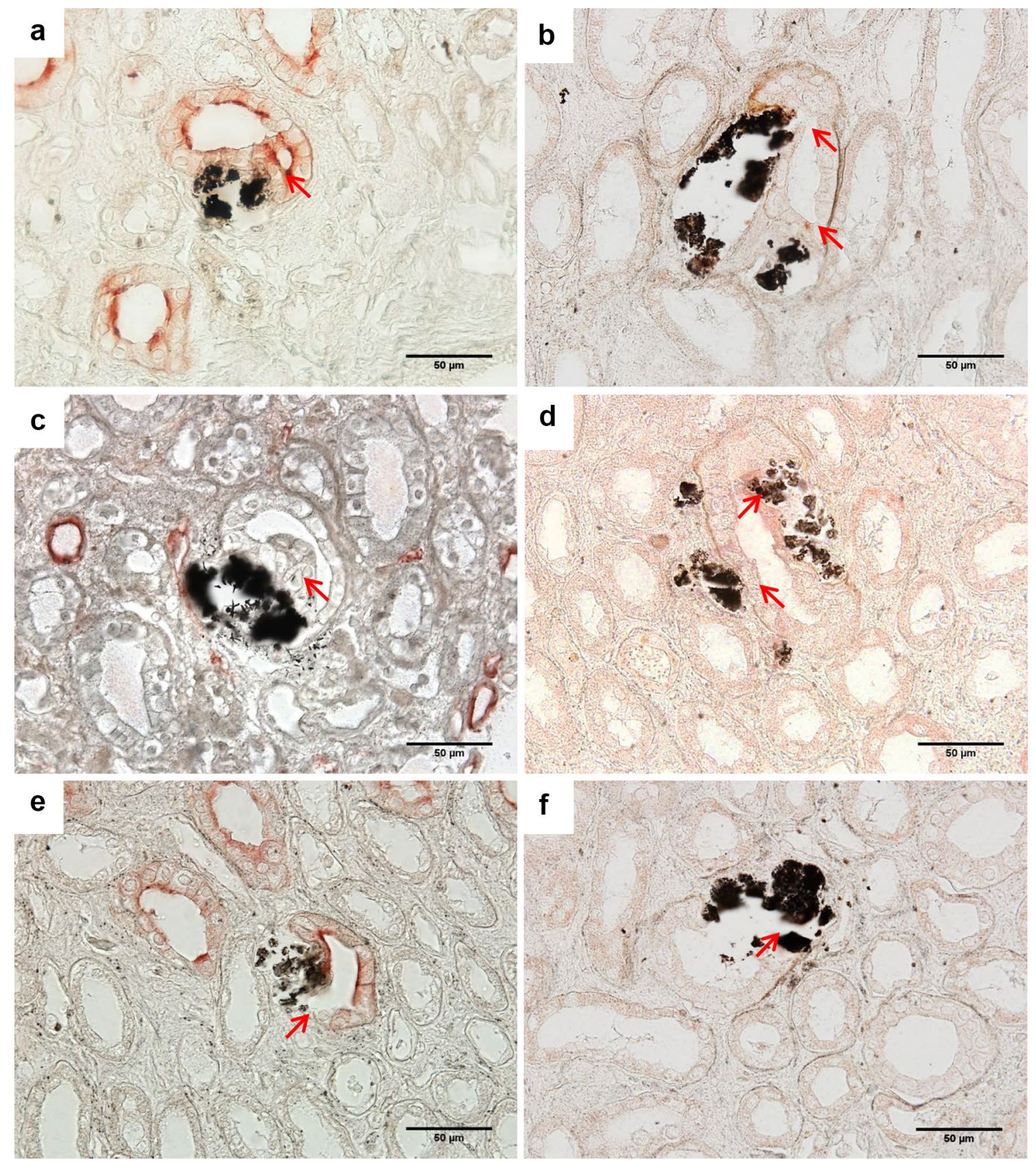

Fig. 6 Collecting duct deformation induced by crystalline plugs. Immunohistochemistry and Yasue staining (photonic microscopy, $\times 600$ ). Crystalline plugs promote collecting duct deformation $(\mathbf{a}-\mathbf{d})$ and in some cases rupture of the epithelium (e-f) (red arrows). Immu-

patients. Since we collected papillae slices, we cannot estimate the number of plugs contained in one human papillae; this would require micro- or nano-computed tomography analyses of the whole papilla. There is no proof that these plugs may be the first step toward kidney stone formation but their high incidence is puzzling and evidences that tubular plugging is a common mechanism. It would be of interest to collect papillae from stone formers and to compare the nostaining corresponds to AQP2/collecting ducts (a, e), WNK4/distal tubule and to a lesser extent collecting duct (b, d, f) and AQP1/ descending loop of Henle (c)

topography, composition and number of tubular plugs to non-stone formers papillae, but this stands beyond the scope of this study. We ignore why there is a such high incidence of tubular plugs in "normal" papillae but it seems likely that calcium phosphate supersaturation at the tip of the papilla is the main driving force leading to plug formation. The high incidence of plug formation also suggests that other mechanisms are required before clinical stone formation 
and that tubular plugging is not sufficient. Conversely, the observation of calcium phosphate tubular plugs in human papillae should not necessarily be considered as a specific pathological process.

The second matter of interest was the various compositions of these plugs. As expected, CA and ACCP were frequently observed, and associated in many cases. We also observed an OCP plug in one patient. OCP is a rare stone component in common lithogenic conditions and has been described in pregnancy-related stones [16]. Pregnancyrelated stones occur rapidly in calcium phosphate supersaturation conditions (high urine $\mathrm{pH}$, hypercalciuria, hyperphosphaturia). OCP is an unstable calcium phosphate that may transform into CA over time and one may hypothesize that in some individuals, OCP plugs may be a transitory phase toward CA plug formation. The identification of calcium carbonate plugs (calcite) was also surprising since pure calcite stones are rare in humans. Calcite formation requires high $\mathrm{pH}$ (carbonate) and high calcium concentration. The proportion of carbonate is highly variable in calcium phosphate kidney stones and it would be of interest to understand in which part of the tubule calcium carbonate may be observed [17]. Unfortunately, colocalization experiments in this patient were not contributive. We also observed calcium and magnesium phosphate (whitlockite) in one individual. Whitlockite may be identified in infection stones and we previously identified by FTIR large amounts of whitlockite in incipient Randall's plaque [13, 18, 19]. The patient affected by whitlockite plugs had also abundant interstitial calcifications (Randall's plaque). Interestingly, brushite signature has not been identified in any case, although its presence in tubular plugs has been mentioned previously [20]. One may hypothesize that brushite plugs may be observed in kidney stone formers only.

We did not find any colocalization of calcium phosphates with AQP1 or Barttin. In some exceptional cases, we identified calcium phosphates plugs in collecting ducts (colocalization with AQP2) and sometimes in distal tubule (colocalization with WNK4). It seems likely that most of calcium phosphate deposits stood in the deepest part of the loop of Henle. This is not unexpected. Actually, plugs are usually considered to result from excessive urinary supersaturation and calcium concentration is predicted to be maximal at the tip of the papilla [21]. Accordingly, plugs were frequent in the papilla and the inner medulla but sparse in the outer medulla and cortex. Interestingly, in the papillae in which calcium oxalate was found, no association with phosphates was observed. Moreover, COM and COD crystalline plugs stood in moderately dilated collecting ducts expressing AQP2. This observation is in accordance with preliminary reports evidencing calcium oxalate plug formation in collecting ducts [10]. COM and COD plugs found in dilated collecting ducts suggest either that multiple plugs were responsible for upstream duct dilation, or that dilated collecting ducts disturb urine flow, promoting calcium oxalate crystals retention.

An unexpected finding was the observation in several patients that plugs could deform adjacent structures, especially collecting ducts and in some cases promote collecting duct epithelium rupture. Whether this process allows elimination of large plugs in urine through collecting ducts remains to be confirmed. Interestingly, animal models of kidneys stones and nephrocalcinosis were characterized by calcium phosphate plugs in kidney tubules and crystal translocation to the interstitium, highlighting that calcium phosphate deposits can, in some conditions, cross the epithelium [22, 23]. Long-term experimental animal models of intratubular calcium phosphate precipitation could be of help to analyse whether calcium phosphate tubular plugs are able to promote collecting duct deformation and at last their rupture.

The major limit of our study is the absence of clinical data, due to study design. We were, therefore, unable to correlate urine biochemistry to the presence of plugs or to their composition. Further, we presumed that tubular plugs may be a first step toward kidney stone formation but we ignore whether plugs present in the ascending loop of Henle could migrate downstream, toward collecting duct and renal cavities. According to tubule diameter downstream of the thin part of the loop of Henle, this hypothesis seems likely but remains speculative. At last, we are extremely cautious with our results relative to plug localization in the tubular lumen. Actually, massive plugs may mask epithelial cells, this is the reason why we did not provide quantitative data regarding plug localization. The observations reported above deserve further studies. As nephrolithiasis is a frequent disease, the collection of healthy papillae from stone formers affected by cancer should be possible in the long term, and a comparison between papillae from stone formers and non-stone formers could provide meaningful outcomes.

\section{Conclusion}

The systematic analysis of renal papillae sections from nonstone formers highlights that tubular plug formation is a very frequent process probably affecting most of the people. The polymorphism and the unexpected variety of these plugs suggest that their composition may vary according to urine composition and to the part of the nephron where they form. In addition, tubular plasticity in response to these plugs is impressive. The observation of tubular plugs deforming and sometimes eroding collecting ducts deserves further studies to understand their potential role in kidney stone formation. 


\section{Compliance with ethical standards}

Funding This work has been supported by the Agence Nationale de la Recherche (ANR-13-JSV1-0010-01, ANR-12-BS08-0022), the Société de Néphrologie (Genzyme Grant), the Académie Nationale de Médecine (Nestlé-Waters award), Convergence-UPMC CVG1205 and CORDDIM-2013-COD130042.

Conflict of interest All authors declare to have no conflict of interest.

Human and animal rights statement All procedures performed in studies involving human participants were in accordance with the ethical standards of the institutional and/or national research committee and with the 1964 Helsinki declaration and its later amendments or comparable ethical standards.

Informed consent Informed consent was obtained from all individual participants included in the study.

\section{References}

1. Trinchieri A (2006) Epidemiological trends in urolithiasis: impact on our health care systems. Urol Res 34:151-156

2. Denstedt JD, Fuller A (2012) Epidemiology of stone disease in North America. In: Talati JJ, Tiselius H-G, Albala DM, YE Z (eds) Urolithiasis. Springer, London, pp 13-20

3. Hesse A, Brändle E, Wilbert D et al (2003) Study on the prevalence and incidence of urolithiasis in Germany comparing the years 1979 vs. 2000. Eur Urol 44:709-713

4. Ogawa Y (2012) Epidemiology of stone disease over a 40-year period in Japan. In: Talati JJ, Tiselius H-G, Albala DM, YE Z (eds) Urolithiasis. Springer, London, pp 89-96

5. Coe FL, Evan AP, Worcester EM et al (2010) Three pathways for human kidney stone formation. Urol Res 38:147-160

6. Randall A (1937) The origin and growth of renal calculi. Ann Surg 105:1009-1027

7. Evan AP, Lingeman JE, Coe FL et al (2003) Randall's plaque of patients with nephrolithiasis begins in basement membranes of thin loop of Henle. J Clin Invest 111:607-616

8. Low RK, Stoller ML (1997) Endoscopic mapping of renal papillae for Randall's plaques in patients with urinary stone disease. J Urol 158:2062-2064
9. Linnes MP, Krambeck AE, Cornell L et al (2013) Phenotypic characterization of kidney stone formers by endoscopic and histological quantification of intrarenal calcification. Kidney Int $84: 818-825$

10. Coe FL, Evan AP, Lingeman JE, Worcester EM (2010) Plaque and deposits in nine human stone diseases. Urol Res 38:239-247

11. Kuo RL, Lingeman JE, Evan AP et al (2003) Urine calcium and volume predict coverage of renal papilla by Randall's plaque. Kidney Int 64:2150-2154

12. Evan AP, Lingeman J, Coe F et al (2007) Renal histopathology of stone-forming patients with distal renal tubular acidosis. Kidney Int 71:795-801

13. Verrier C, Bazin D, Huguet L et al (2016) Topography, composition and structure of incipient Randall plaque at the nanoscale level. J Urol 196:1566-1574

14. Khan SR (2004) Role of renal epithelial cells in the initiation of calcium oxalate stones. Nephron Exp Nephrol 98:e55-e60

15. Khan SR, Hackett RL (1991) Retention of calcium oxalate crystals in renal tubules. Scanning Microsc 5:707-711

16. Meria P, Hadjadj H, Jungers $P$ et al (2010) Stone formation and pregnancy: pathophysiological insights gained from morphoconstitutional stone analysis. J Urol 183:1412-1416

17. Maurice-Estepa L, Levillain P et al (1999) Crystalline phase differentiation in urinary calcium phosphate and magnesium phosphate calculi. Scand J Urol Nephrol 33:99-305

18. Carpentier X, Daudon M, Traxer O et al (2009) Relationships between carbonation rate of carbapatite and morphologic characteristics of calcium phosphate stones and etiology. Urology 73:968-975

19. Daudon M, Bazin D (2016) Vibrational spectroscopies to investigate concretions and ectopic calcifications for medical diagnosis. C R Chimie 19:1416-1423

20. Evan AP, Lingeman JE, Worcester EM et al (2014) Contrasting histopathology and crystal deposits in kidneys of idiopathic stone formers who produce hydroxy apatite, brushite, or calcium oxalate stones. Anat Rec 297:731-748

21. Tournus M, Seguin N, Perthame B et al (2013) A model of calcium transport along the rat nephron. Am J Physiol Renal Nephrol 305:F979-F994

22. Khan SR, Glenton PA (2008) Calcium oxalate crystal deposition in kidneys of hypercalciuric mice with disrupted type IIa sodium-phosphate cotransporter. Am J Physiol Renal Physiol 294:F1109-F1115

23. Khan SR (2017) Histological aspects of the "fixed-particle" model of stone formation in animal studies. Urolithiasis 45:75-87 